\title{
Elizabethkingia Infections in Humans: From Genomics to Clinics
}

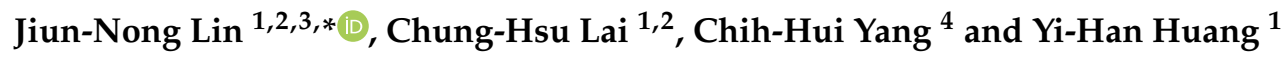 \\ 1 School of Medicine, College of Medicine, I-Shou University, Kaohsiung 824, Taiwan \\ 2 Division of Infectious Diseases, Department of Internal Medicine, E-Da Hospital, I-Shou University, \\ Kaohsiung 824, Taiwan \\ 3 Department of Critical Care Medicine, E-Da Hospital, I-Shou University, Kaohsiung 824, Taiwan \\ 4 Department of Biological Science and Technology, Meiho University, Pingtung 912, Taiwan \\ * Correspondence: jinoli@kmu.edu.tw; Tel.: +886-7-6150011-251469; Fax: +886-7-615-0928
}

Received: 7 August 2019; Accepted: 27 August 2019; Published: 28 August 2019

\begin{abstract}
The genus Elizabethkingia has recently emerged as a cause of life-threatening infections in humans, particularly in immunocompromised patients. Several new species in the genus Elizabethkingia have been proposed in the last decade. Numerous studies have indicated that Elizabethkingia anophelis, rather than Elizabethkingia meningoseptica, is the most prevalent pathogen in this genus. Matrix-assisted laser desorption/ionization-time of flight mass spectrometry systems with an extended spectrum database could reliably identify E. anophelis and E. meningoseptica, but they are unable to distinguish the remaining species. Precise species identification relies on molecular techniques, such as housekeeping gene sequencing and whole-genome sequencing. These microorganisms are usually susceptible to minocycline but resistant to most $\beta$-lactams, $\beta$-lactam/ $\beta$-lactam inhibitors, carbapenems, and aminoglycosides. They often exhibit variable susceptibility to piperacillin, piperacillin-tazobactam, fluoroquinolones, and trimethoprim-sulfamethoxazole. Accordingly, treatment should be guided by antimicrobial susceptibility testing. Target gene mutations are markedly associated with fluoroquinolone resistance. Knowledge on the genomic characteristics provides valuable insights into in these emerging pathogens.
\end{abstract}

Keywords: Elizabethkingia meningoseptica; Elizabethkingia miricola; Elizabethkingia anophelis; Elizabethkingia bruuniana; Elizabethkingia ursingii; Elizabethkingia occulta; epidemiology; drug resistance; genomics

\section{Introduction}

Microorganisms in the genus Elizabethkingia are Gram-negative, aerobic, pale yellow-pigmented, nonmotile, glucose-non-fermenting, non-spore-forming, oxidase-positive, weakly indole-positive, and nitrate-negative bacilli (Figure 1) [1,2]. These bacteria are ubiquitously distributed in natural environments such as water, soils, fish, frogs, and insects [3-8], as well as in the tap water of hospitals [9-11]. Since its first identification in 1959 [12], Elizabethkingia has been occasionally reported to cause human infections. Recently, these bacteria have emerged as a major cause of life-threatening infections in numerous countries [13-22].

Along with advances in genetics and molecular technology, high-throughput next-generation sequencing has become a powerful tool in research and clinical medicine. Whole-genome sequencing has been widely used to investigate the genomic features, evolutionary relationship, epidemiology, species delineation, virulence factors, and antibiotic resistance of microorganisms, particularly in emerging pathogens $[23,24]$. Herein, we review the literature related to the genomic studies and the taxonomy, species identification, epidemiology, clinical characteristics, and antimicrobial susceptibility 
testing of Elizabethkingia infections in humans. This review provides insights into the genomics and clinics of this emerging infection.

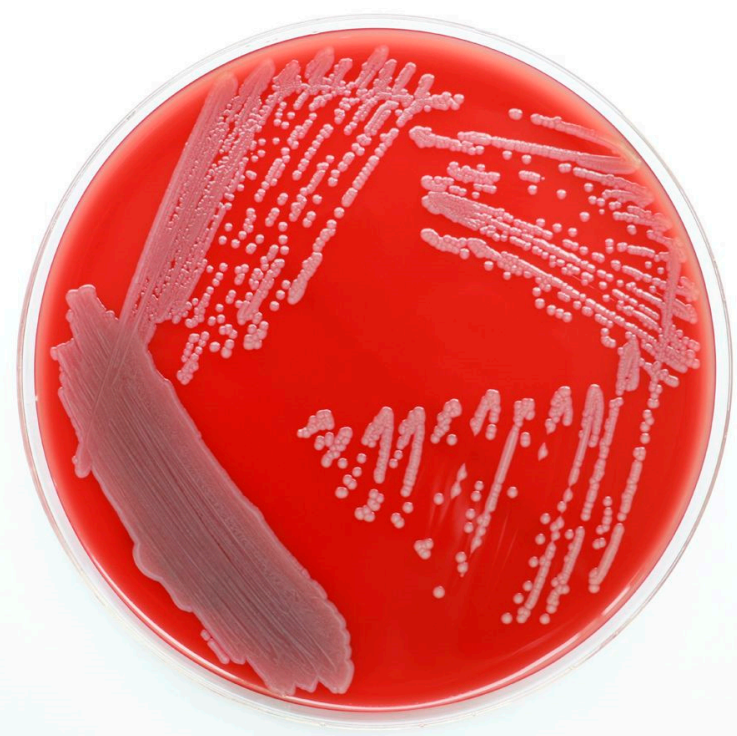

Figure 1. Elizabethkingia meningoseptica on sheep blood agar after $48 \mathrm{~h}$ of incubation.

\section{Taxonomy and Nomenclature}

In the 1950s, an increase in meningitis in infants caused by an unknown Gram-negative rod-shaped bacterium attracted attention in the United States. This unclassified bacterium was designated as group IIa by the US Centers for Disease Control and Prevention (CDC). In 1959, an American microbiologist at the CDC, Elizabeth O. King, investigated this pathogen and named it Flavobacterium meningosepticum (Table 1) [12]. This bacterium was moved to a new genus and renamed Chryseobacterium meningosepticum in 1994 [25]. Kim et al. proposed Elizabethkingia gen. nov. later, and C. meningosepticum was then renamed Elizabethkingia meningoseptica in 2005 [1].

In 2003, Li et al. identified a novel species, Chryseobacterium miricola, from condensation water collected in 1997 on the Mir space station of Russia [26]. This new species was assigned to the genus Elizabethkingia along with E. meningoseptica and was renamed Elizabethkingia miricola [1]. The third species, Elizabethkingia anophelis, was recovered from the midgut of Anopheles gambiae mosquitos in the Gambia, Africa, by Kämpfer et al. in 2011 [3]. Four years later, Elizabethkingia endophytica sp. nov. (type strain JM-87 ${ }^{\mathrm{T}}$ ) was proposed [27]. However, this strain was recognized as a later subjective synonym of E. anophelis as per the comparative genomics of whole-genome sequencing [28]. In August 2017, Nicholson et al. investigated bacteria of the unknown CDC genomospecies, and Elizabethkingia bruuniana, Elizabethkingia ursingii, and Elizabethkingia occulta were proposed as new members of the genus Elizabethkingia [2]. Currently, the genus Elizabethkingia comprises six species, namely, E. meningoseptica, E. miricola, E. anophelis, E. bruuniana, E. ursingii, and E. occulta. 
Table 1. Taxonomy and nomenclature of Elizabethkingia species.

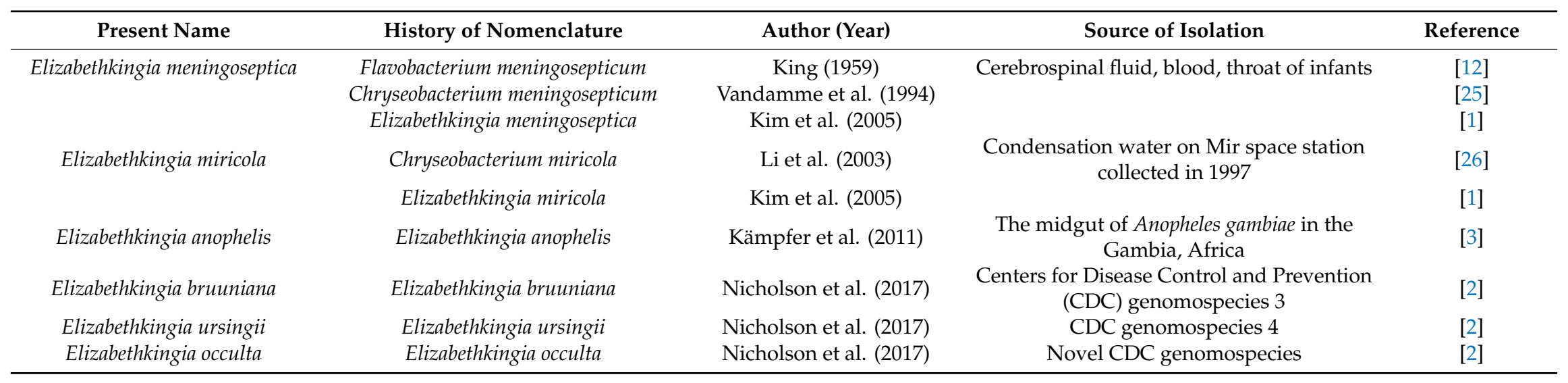




\section{Identification of Species}

Accurately identifying offensive pathogens, either for clinical practice or basic research, is imperative. However, the identification of Elizabethkingia species remains a considerable challenge in clinical settings.

\subsection{Biochemical-Based Phenotyping and Matrix-Assisted Laser Desorption/Ionization-Time of Flight Mass Spectrometry}

Both biochemical-based phenotyping and matrix-assisted laser desorption/ionization-time of flight mass spectrometry (MALDI-TOF MS) systems are extensively used for microbial identification in clinical microbiology laboratories. The most widely used microbial identification systems include API/ID32 Phenotyping Kits (bioMérieux, Marcy l'Etoile, France), Phoenix 100 ID/AST Automated Microbiology System (Becton Dickinson Co., Sparks, MD, USA), Vitek 2 Automated Identification System (bioMérieux), Vitek MS (bioMérieux), and Bruker Biotyper MS (Bruker Daltonics GmbH, Bremen, Germany). However, these systems contain only a portion of Elizabethkingia species in their reference databases (Table 2). The newly proposed Elizabethkingia species are actually not included in the reference databases of these commercial identification systems. The lack of species information in the reference databases prevents these platforms from correctly recognizing the species of Elizabethkingia.

Table 2. The coverage of the reference database of five common commercial microbial identification systems.

\begin{tabular}{cccccc}
\hline Species & API/ID32 v3.1 & $\begin{array}{c}\text { Phoenix 100 } \\
\text { ID/AST v5.51A }\end{array}$ & Vitek 2 v7.01 & $\begin{array}{c}\text { Bruker } \\
\text { Vitek MS } \\
\text { Knowledge } \\
\text { Base v2.0/v3.0 }\end{array}$ & $\begin{array}{c}\text { Biotyper } \\
\text { Reference } \\
\text { Library v6.0 } \\
\mathbf{6 9 0 3}\end{array}$ \\
\hline E. meningoseptica & Yes & Yes & Yes & Yes & Yes \\
E. miricola & No & Yes & No & No & Yes \\
E. anophelis & No & No & No & No & No \\
E. bruuniana & No & No & No & No & No \\
E. ursingii & No & No & No & No & No \\
E. occulta & No & No & No & No & No \\
\hline
\end{tabular}

Several studies have demonstrated low reliability levels of common microbial identification systems in the identification of Elizabethkingia species. Lin et al. compared the accuracy of API/ID32, Phoenix 100 ID/AST, Vitek 2, and Vitek MS with that of 16S ribosomal RNA (rRNA) gene sequencing for the identification of 49 Elizabethkingia isolates in Taiwan [29]. The concordances of species identification between these machines and $16 \mathrm{~S}$ rRNA gene sequencing were only $24.5 \%-26.5 \%$. Lau et al. retrospectively analyzed 21 Elizabethkingia isolates in Hong Kong [14], namely 17 E. anophelis, three E. meningoseptica, and one E. miricola, as determined through 16S rRNA gene sequencing. All isolates were identified as E. meningoseptica by Vitek 2; the 17 E. anophelis were misidentified as E. meningoseptica or unidentified by the Bruker Biotyper equipped with a default spectrum library. In another retrospective study performed in South Korea [30], Han et al. investigated 51 E. anophelis, 17 E. meningoseptica, and 18 E. miricola species. Similar to the report of Lau et al. [14], E. meningoseptica could be accurately identified by Vitek 2, Vitek MS, and Bruker Biotyper, but almost all E. anophelis species were misidentified as E. meningoseptica by Vitek 2 and MALDI-TOF MS with a default database.

Although MALDI-TOF MS systems equipped with commercial reference databases cannot recognize E. anophelis, systems with amended databases—such as the "research-use-only" (Saramis) database of Vitek MS [30,31], in-house expanded spectrum database of Bruker Biotyper [14], and expanded spectral library provided by the CDC Special Bacteriology Reference Laboratory of Bruker Biotyper [15] — could reliably distinguish E. anophelis from E. meningoseptica. Cheng et al. investigated the specific peaks of each Elizabethkingia species using the Vitek MS research-use-only system [31]. Some specific mass-to-charge ratio $(\mathrm{m} / \mathrm{z})$ values, namely, peaks at 7643.7/10320.9 $\mathrm{m} / \mathrm{z}$ in 
E. anophelis, 3141.5/12109.1 $\mathrm{m} / \mathrm{z}$ in E. meningoseptica, and 3792.5/7586.6 m/z in E. miricola cluster, were observed. These specific peaks in MALDI-TOF MS could be used to differentiate Elizabethkingia species. However, these amended databases, either in the Vitek MS or Bruker Biotyper systems, are primarily available for research purposes but are not for clinical application in clinical microbiology laboratories. Additionally, although MALDI-TOF MS systems with expanded spectrum databases could reliably identify E. anophelis and E. meningoseptica, these platforms cannot distinguish between the remaining species of the genus Elizabethkingia [2,31].

\subsection{Housekeeping Gene Sequencing}

Housekeeping gene sequencing has been increasingly used for microbial identification. Among the genotyping techniques of housekeeping gene sequencing, 16S rRNA and RNA polymerase $\beta$-subunit $(r p o B)$ gene sequencing are the two most commonly used methods for microbial identification [32,33].

In the literature, $16 \mathrm{~S}$ rRNA gene sequencing is considered an accurate method for identifying Elizabethkingia species [34]. The total length of the 16S rRNA gene in Elizabethkingia species is 1521 bp $[14,18,19]$. The $16 \mathrm{~S}$ rRNA gene includes nine hypervariable regions V1-V9 and these regions possess varying lengths and conservation in different bacterial species. Some of the hypervariable regions exhibit more variabilities than others [32]. However, no studies to date investigate the $16 \mathrm{~S}$ rRNA hypervariable regions in Elizabethkingia species. Moreover, the existence of multiple $16 \mathrm{~S}$ rRNA copies with different sequences in bacteria has advanced the argument for the use of 16S rRNA gene sequencing in microbial identification [35]. For example, five $16 \mathrm{~S}$ rRNA gene copies in an E. ursingii strain were discovered; one $16 \mathrm{~S}$ rRNA gene was similar to the E. ursingii type strain G4122 ${ }^{\mathrm{T}}$, two were similar to E. bruuniana, and the remaining two matched each other but were otherwise unique [2]. Therefore, species identification using $16 \mathrm{~S}$ rRNA gene sequencing could be misleading.

$r p o B$ is highly conserved in microorganisms and has become a potential candidate for microbial identification [36,37]. rроB typically presents with a single copy, and it possesses a higher resolution of phylogenetic evolution than does the 16S rRNA gene [33]. A molecular phylogenetic analysis of rpoB at positions 1939-3629 was proved to be able to correctly distinguish Elizabethkingia strains at the species level [2]. However, studies have yet to compare the accuracy of $16 \mathrm{~S}$ rRNA and rpoB gene sequencing in identifying species in the genus Elizabethkingia.

\subsection{Polymerase Chain Reaction Assay}

Two polymerase chain reaction (PCR)-based methods have been recently developed for detecting and differentiating Elizabethkingia [38,39]. After a comparative analysis of the whole-genome sequences of different Elizabethkingia species, species-specific genes in E. anophelis (encoding lipid A-disaccharide synthase) and E. meningoseptica (a putative gene of sodium-proton antiporter) were explored. The amplicon sizes for the differentiation of E. anophelis and E. meningoseptica were $281 \mathrm{bp}$ and $250 \mathrm{bp}$, respectively. This method could clearly discriminate E. anophelis from E. meningoseptica with no cross-reactivity [38]. In addition, a multiplex real-time PCR technique was developed for detecting Elizabethkingia bacteria directly from primary specimens and discriminating E. anophelis and E. meningoseptica [39]. The highly conserved sec $Y$ gene (PCR amplicon size, $146 \mathrm{bp}$ ) in all species was selected as a representative target of the genus Elizabethkingia. The elongation factor 4 lepA gene (PCR amplicon size, $142 \mathrm{bp}$ ) and phenylalanine-tRNA ligase $\beta$-subunit pheT gene (PCR amplicon size, $90 \mathrm{bp}$ ) were chosen to discriminate E. anophelis from E. meningoseptica [39]. These PCR assays emphasise the rapid and reliable recognition of the presence of Elizabethkingia species, and they simultaneously distinguish E. anophelis from E. meningoseptica [39].

\subsection{Species Delineation through Whole-Genome Sequencing}

DNA-DNA hybridization (DDH) has clearly served as the gold standard for distinguishing bacterial species since the 1960s [40]. However, conventional DDH is a complex and time-consuming procedure and is usually available only in some laboratories. With the introduction of high-throughput 
next-generation sequencing, whole-genome sequencing has been increasingly used in the species delineation of microorganisms $[23,24]$. Whole-genome sequence-based average nucleotide identity (ANI) analysis and in silico DDH are widely acknowledged as the two robust measures of genomic similarity between different strains $[23,24,41,42]$. These two methods have been demonstrated to yield a higher correlation than conventional DDH in the delineation of prokaryotic species $[23,24,41,42]$. Despite these merits, whole-genome sequencing remains a highly expensive and time-consuming procedure. Thus, the application of whole-genome sequencing in species delineation is usually limited in research.

Whole-genome sequencing is valuable in taxonomy for determining the relatedness of different species [2,28]. A number of whole-genome sequences of Elizabethkingia species are available in the GenBank of the National Center for Biotechnology Information [2,28,43-47]. The complete genome size of Elizabethkingia species is approximately $4.3-4.4 \mathrm{Mbp}$, and contains approximately 4000 coding sequences $[2,3,27,43-47]$. As mentioned, E. endophytica was proposed as a novel species in the genus Elizabethkingia [27]. However, the in silico DDH and ANI values between the E. endophytica type strain $\mathrm{JM} 87^{\mathrm{T}}$ and E. anophelis type strain $\mathrm{R} 26^{\mathrm{T}}$ were $77 \%$ (cutoff value of species delimitation, $70 \%$ ) and $97 \%$ (cutoff value of species delimitation, 95\%), respectively [28]. This finding suggests that E. endophytica actually represents a strain of E. anophelis and not a new species. In addition, substantial sequence variability in the whole-genome sequences of E. miricola strains has been observed [28,45]. According to the results of in silico DDH and ANI analyses, some strains of E. miricola, including ATCC 33958, BM10, and EM798-26, have been reassigned as E. bruuniana $[2,43,46]$.

\section{Epidemiology, Clinical Characteristics, and Outcomes}

\subsection{E. meningoseptica}

As mentioned, several Elizabethkingia species were misidentified as E. meningoseptica. Therefore, previous studies on the epidemiology and clinical features of E. meningoseptica could have substantial bias if they were performed before the proposal of novel species or species identification relying on inaccurate methods [48-57].

The incidence of E. meningoseptica infection is not entirely clear. A South Korean study reported that the annual incidence of E. meningoseptica infection was 0.01 per 1000 admissions in 2009 and then increased to 0.04 per 1000 admissions from 2016-2017 [17]. Actually, E. meningoseptica only accounted for approximately $1 \%-21 \%$ of all Elizabethkingia pathogens isolated from clinical specimens. By contrast, E. anophelis was the most prevalent pathogen in this genus, constituting $59 \%-99 \%$ of all isolates $[14,17,18,30]$.

The majority of E. meningoseptica infections present as meningitis, bacteremia, pneumonia, skin and soft-tissue infection, catheter-associated infection, and urinary tract infection in neonates, infants, and immunocompromised patients [49-52,58,59]. Most cases were attributed to health care-associated infections, and over $85 \%$ of patients had at least one comorbidity [19]. The case-fatality rate of E. meningoseptica-infected patients has been reported to be $30 \%-54 \%[9,19]$. An epidemiologic investigation revealed that water is a transmission route of E. meningoseptica infection in hospitals [9].

\subsection{E. miricola}

E. miricola has been sporadically reported to cause pneumonia, bacteremia, urinary tract infection, and periodontitis since its first proposal as a new species in 2003 [60-63]. A retrospective South Korean study reported that the annual incidence of E. miricola increased from 0 to 0.22 per 1000 admissions from 2009-2016 [17]. Nevertheless, the prevalence of E. miricola markedly varies in different geographic areas $[14,29,31,38]$. A Singapore study retrospectively analyzed 79 bacteremic Elizabethkingia isolates collected from 2009-2019, and no E. miricola was identified using 16S rRNA gene sequencing [38]. Studies in Hong Kong [14] and Taiwan [29] have reported that only one E. anophelis isolate was recognized from a collection of 21 and 49 Elizabethkingia isolates, respectively. However, another study 
performed in northern Taiwan discovered 18 isolates of E. miricola among 269 Elizabethkingia isolates through rрoB sequencing [31]. Recently, E. miricola appears to have become a vital opportunistic pathogen in patients with cystic fibrosis in the United Kingdom [64]. Kenna et al. reported that 43 isolates from 38 patients with cystic fibrosis congregated in a cluster that shared $>99 \%$ rpoB sequence similarity with the type strains of E. miricola and E. bruuniana. However, the species in this "E. miricola and E. bruuniana cluster" could not be precisely distinguished in that study [64].

\subsection{E. anophelis}

The first case of E. anophelis infection was reported in a neonatal meningitis patient in the Central African Republic in 2011 [13]. Thereafter, several studies have demonstrated that E. anophelis has recently emerged as a life-threatening infection in Singapore [11], Hong Kong [14], the United States [15,16,20,21], South Korea [17], and Taiwan [18]. However, as mentioned, E. anophelis is usually misidentified as E. meningoseptica by microbial identification platforms in clinical settings. Therefore, the incidence of $E$. anophelis infection could be substantially underestimated.

Several outbreaks of E. anophelis infection in humans have been described. In 2012, an outbreak occurred in five patients in an intensive care unit in Singapore, resulting in two deaths due to sepsis [11]. The largest outbreak to date was described in the Midwestern United States-Wisconsin, Illinois, and Michigan-from 2015-2017 [15,16,20,21]. A total of 63 patients were confirmed to have E. anophelis infection in Wisconsin, and this outbreak caused 19 deaths [20]. Another outbreak affecting ten patients occurred in Illinois, and six of these patients died of this infection [21]. Despite these outbreak announcements, the actual prevalence of E. anophelis infection is unclear. Only one study in South Korea reported that the annual incidence of E. anophelis infection increased from 0.01 to 0.6 per 1000 admissions from 2009-2017 [17].

The transmission route of E. anophelis remains unclear. E. anophelis is suspected to be transmitted by an insect vector considering that $E$. anophelis was originally discovered in the A. gambiae mosquito [3]. However, currently, evidence supporting that E. anophelis infection is a mosquito-borne disease is unavailable. Investigations of the infection source in the Midwest outbreak remain undetermined despite aggressive examinations of tap water, food, and personal hygiene products $[15,16,20,21]$. Perinatal vertical transmission from mother to infant has been established in Hong Kong through a whole-genome analysis of the offending strains [65]. In addition, an epidemiologic investigation of outbreaks in Singapore revealed E. anophelis in the tap water aerators of the hospital [10,11]. E. anophelis was suggested to be transmitted from the hands of health care workers, who acquired this bacterium during handwashing, to patients. The removal of the aerators and the use of alcohol-based hand rubs after hand hygiene could effectively eliminate the transmission of E. anophelis [10].

The clinical presentations of E. anophelis infections are protean, including bacteremia, pneumonia, catheter-related bloodstream infection, meningitis, skin and soft-tissue infection, urinary tract infection, and biliary tract infection [14,19-21]. Most infections (80\%-87.5\%) are hospital-acquired [14,19]. However, $89 \%$ of cases in the Wisconsin outbreak were attributed to community-onset infection $[15,16$, 20,21]. Patients with E. anophelis infection are usually over 60 years old, and over $85 \%$ of patients have comorbidities, such as diabetes mellitus, malignancy, chronic renal disease, end-stage renal disease with dialysis therapy, liver cirrhosis, alcohol dependence, immune-compromising conditions, and receiving immunosuppressive treatment [14-21]. The case-fatality rate of patients with E. anophelis infection is critically high, ranging from $24 \%$ to $60 \%$ [14-21]. Notably, inappropriate empirical antimicrobial therapy is an independent risk factor for mortality in patients infected with E. anophelis $[18,19]$.

\subsection{Other Elizabethkingia Species}

After the proposal of E. bruuniana, E. ursingii, and E. occulta, only a few studies have discussed these novel species. In the aforementioned study on patients with cystic fibrosis in the United Kingdom [64], one isolate expressed $99.3 \%$ similarity of rpoB with the type strain of E. ursingii, and 43 isolates formed an 'E. miricola and E. bruuniana cluster'. However, E. bruuniana could not be differentiated from 
E. miricola. A study from Taiwan retrospectively analyzed 269 Elizabethkingia isolates by using $16 \mathrm{~S}$ rRNA and rpoB sequencing, and one E. bruuniana and two E. occulta were recognized [31]. Another study published the complete whole-genome sequence of the E. miricola strain EM798-26, which was isolated from the blood of an 81-year-old male patient with diffuse large B-cell lymphoma in Taiwan [46]. After a comprehensive genomic investigation, this strain was amended as E. bruuniana. Recently, six patients with health care-associated E. bruuniana infections were reported in Taiwan using $16 \mathrm{~S}$ rRNA and rpoB gene sequencing [66]. The isolation sources of E. bruuniana included blood, bronchoalveolar lavage fluid, urine, and the tip of the central venous catheter. None of the patients died of E. bruuniana infection [66].

\section{Antimicrobial Susceptibility Testing and Antibiotic Resistance Genes}

The antimicrobial susceptibility patterns of Elizabethkingia reported in the literature are summarized in Table 3. Notably, the antibiotic susceptibilities, particularly for vancomycin and piperacillin-tazobactam, determined by the disk diffusion test, E-test assay, and agar dilution test are considered to be unreliable and inaccurate for Elizabethkingia species [67]. The broth microdilution test is recommended for susceptibility determination. However, only two studies from Taiwan $[19,31]$ and one from Singapore [38] have employed the broth microdilution method to determine the antibiotic susceptibility for Elizabethkingia species.

\subsection{E. meningoseptica}

Most studies investigating the antimicrobial resistance of E. meningoseptica were performed before the proposal of E. anophelis. As mentioned, these studies have actually represented the antimicrobial susceptibility patterns of all Elizabethkingia species, particularly E. anophelis, but not those of E. meningoseptica. Currently, only a few studies have examined the antimicrobial susceptibility of a collection of E. meningoseptica by using reliable species identification methods (Table 3).

Studies have revealed that E. meningoseptica isolates were usually resistant to cephalosporins, carbapenems, and aminoglycosides [19,30,31]. These isolates displayed variable susceptibility levels to piperacillin $(15 \%-65 \%)$, piperacillin-tazobactam $(5 \%-100 \%)$, ciprofloxacin $(10 \%-23 \%)$, and levofloxacin $(30 \%-55 \%)$. The rate of susceptibility to trimethoprim-sulfamethoxazole was relatively low $(6 \%-10 \%)$. Most isolates $(60 \%-100 \%)$ were susceptible to minocycline. Notably, no E. meningoseptica was susceptible to vancomycin. Although some anecdotal reports have revealed the successful treatment of E. meningoseptica meningitis using a combination therapy of vancomycin with other antibiotics [68], the use of vancomycin is not suggested because of its high minimum inhibitory concentration $[19,30]$.

Whole-genome research conducted on E. meningoseptica has identified numerous putative genes conferring antibiotic resistance $[19,69]$. However, only a few homologs have been further investigated. Two recent studies have explored the association between fluoroquinolone resistance and target gene mutations in E. meningoseptica $[19,70]$. Several point mutations were detected in the quinolone-resistance-determining regions (QRDRs) of DNA gyrase subunit A (GyrA) and subunit B (GyrB). Amino acid alterations Ser83Ile/Pro95Ser in GyrA and Ser452Arg/Glu470Asp in GyrB were significantly associated with levofloxacin resistance $[19,70]$. 
Table 3. The antibiotic susceptible rate of Elizabethkingia species.*.

\begin{tabular}{|c|c|c|c|c|c|c|c|c|c|c|c|}
\hline \multirow{3}{*}{ Antimicrobial Agent } & \multicolumn{3}{|c|}{ E. meningoseptica } & \multicolumn{2}{|c|}{ E. miricola } & \multicolumn{6}{|c|}{ E. anophelis } \\
\hline & $\begin{array}{c}\text { Han et al. } \\
{[30]} \\
n=17\end{array}$ & $\begin{array}{c}\text { Cheng et } \\
\text { al. [31] } \\
n=11\end{array}$ & $\begin{array}{c}\text { Lin et al. } \\
{[19]} \\
n=20\end{array}$ & $\begin{array}{c}\text { Han et al. } \\
{[30]} \\
n=18\end{array}$ & $\begin{array}{c}\text { Cheng et } \\
\text { al. [31] } \\
n=22^{+}\end{array}$ & $\begin{array}{c}\text { Lau et al. } \\
{[14]} \\
n=17\end{array}$ & $\begin{array}{c}\text { Han et al. } \\
{[30]} \\
n=51\end{array}$ & $\begin{array}{c}\text { Perrin et al. } \\
{[15]} \\
n=25\end{array}$ & $\begin{array}{c}\text { Cheng et } \\
\text { al. [31] } \\
n=105\end{array}$ & $\begin{array}{c}\text { Chew et al. } \\
\quad[38] \\
n=79 \ddagger\end{array}$ & $\begin{array}{c}\text { Lin et al. } \\
\text { [19] } \\
n=72\end{array}$ \\
\hline & $\begin{array}{l}\text { South } \\
\text { Korea }\end{array}$ & Taiwan & Taiwan & $\begin{array}{l}\text { South } \\
\text { Korea }\end{array}$ & Taiwan & $\begin{array}{l}\text { Hong } \\
\text { Kong }\end{array}$ & $\begin{array}{l}\text { South } \\
\text { Korea }\end{array}$ & USA & Taiwan & Singapore & Taiwan \\
\hline Piperacillin & 65 & - & 15 & 83 & - & $41 \cdot 1$ & 82 & 100 & - & - & $19 \cdot 4$ \\
\hline Piperacillin-tazobactam & 100 & 73 & 5 & 94 & 73 & - & 92 & 92 & 73 & $92 \cdot 4$ & $30 \cdot 6$ \\
\hline Ticarcillin-clavulanic acid & - & 0 & 0 & - & 0 & - & - & - & 0 & 21.5 & 0 \\
\hline Cefoperazone-sulbactam & - & - & - & - & - & 100 & - & - & - & - & - \\
\hline Ceftazidime & 0 & 0 & 0 & 0 & 0 & $5 \cdot 9$ & 0 & 0 & 0 & 0 & 0 \\
\hline Cefepime & - & 0 & 0 & - & 9 & - & - & 92 & 4 & 0 & $2 \cdot 8$ \\
\hline Ceftriaxone & - & - & 0 & - & - & - & - & - & - & - & 0 \\
\hline Aztreonam & - & 0 & 0 & - & 0 & - & - & - & 0 & $1 \cdot 3$ & 0 \\
\hline Ertapenem & - & 0 & 0 & - & 0 & - & - & - & 0 & - & 0 \\
\hline Imipenem & 0 & 0 & 0 & 0 & 0 & 0 & 0 & 0 & 0 & 0 & 0 \\
\hline Meropenem & - & 0 & 0 & - & 0 & - & - & - & 0 & 0 & 0 \\
\hline Doripenem & - & 0 & 0 & - & 0 & - & - & - & 0 & 0 & 0 \\
\hline Gentamicin & 6 & 0 & 0 & 45 & 0 & 0 & 22 & 0 & 0 & $1 \cdot 3$ & 0 \\
\hline Tobramycin & - & 0 & 0 & - & 0 & 0 & - & 0 & 0 & 0 & 0 \\
\hline Amikacin & - & 0 & 0 & - & 9 & 0 & - & 0 & 0 & $6 \cdot 3$ & $5 \cdot 6$ \\
\hline Tetracycline & - & - & 0 & - & - & - & - & - & - & - & 0 \\
\hline Minocycline & - & 100 & 60 & - & 100 & - & - & - & 98 & $97 \cdot 5$ & 100 \\
\hline Doxycycline & - & 91 & - & - & 82 & - & - & - & 83 & $92 \cdot 4$ & - \\
\hline Tigecycline & - & 55 & 15 & - & 50 & - & - & - & 20 & $5 \cdot 1$ & $26 \cdot 4$ \\
\hline Ciprofloxacin & 23 & 0 & 10 & 56 & 14 & 100 & 22 & 92 & 1 & $21 \cdot 5$ & $9 \cdot 7$ \\
\hline Levofloxacin & 35 & 55 & 30 & 100 & 77 & - & 29 & 96 & 16 & 78.5 & $58 \cdot 3$ \\
\hline Moxifloxacin & 41 & - & - & 100 & - & - & 41 & - & - & - & - \\
\hline Gatifloxacin & 35 & - & - & 100 & - & - & 33 & - & - & - & - \\
\hline Trimethoprim-sulfamethoxazole & 6 & 0 & 10 & 28 & 18 & $70 \cdot 6$ & 22 & - & 4 & $92 \cdot 4$ & $12 \cdot 5$ \\
\hline Rifampin & 94 & - & - & 66 & - & $58 \cdot 8$ & 96 & - & - & - & - \\
\hline Vancomycin & 0 & - & 0 & 0 & - & 100 & 0 & - & - & - & 0 \\
\hline
\end{tabular}

* Methods of minimum inhibitory concentration determination: Han et al. [30], agar dilution test; Cheng et al. [31], broth microdilution test; Lin et al. [19], broth microdilution test;

Lau et al. [14], disk diffusion test; Perrin et al. [15], disk diffusion test; and Chew et al. [38], broth microdilution test. " Representing an "E. miricola cluster" that contains E. miricola,

E. bruuniana, E. ursingii, and E. occulta. ${ }^{\ddagger}$ Containing one E. meningoseptica and 78 E. anophelis isolates. 


\subsection{E. miricola}

Similar to E. meningoseptica, E. miricola is usually resistant to multiple antibiotics (Table 3). In analyses of 18 isolates collected in South Korea [30] and 22 isolates obtained in Taiwan [31], all E. miricola isolates were resistant to cephalosporins, aminoglycosides, and carbapenems. These isolates were most susceptible to minocycline $(100 \%)$, levofloxacin $(77 \%-100 \%)$, piperacillin-tazobactam (73\%-94\%), piperacillin (83\%), rifampin (66\%), and ciprofloxacin $(14 \%-56 \%)$.

A Switzerland study recognized genes encoding metallo- $\beta$-lactamases (BlaB-15 and a GOB-7-like enzyme) in a multidrug-resistant E. miricola isolated from the urine of a 2-year-old boy [61]. These genes confer resistance to penicillin- $\beta$-lactamase inhibitor combinations, cefotaxime, cefoxitin, and carbapenems. Another Switzerland study reported a carbapenemase-producing clinical isolate of E. miricola EM_CHUV recovered from the lower respiratory tract specimen of a patient with severe nosocomial pneumonia [62]. This strain was sensitive to gentamicin, amikacin, and levofloxacin but resistant to all tested $\beta$-lactams, $\beta$-lactam $/ \beta$-lactams inhibitor combinations, ciprofloxacin, and carbapenems. Whole-genome analysis disclosed the presence of numerous antibiotic resistance genes, including $b l a_{\mathrm{GOB}-13}$ and $b l a_{\mathrm{B}-9}$ encoding for class $\mathrm{B}$ carbapenemases. In addition, the amino acid alterations Ser83Ile/Asp87Asn/Thr83Ser in GyrA, Met437Leu in GyrB, and Met437Phe/Ala473Leu in ParE have been detected in some studies $[62,70]$. The presence of abundant antibiotic resistance genes is compatible with multidrug resistance.

\subsection{E. anophelis}

Several studies have demonstrated that $E$. anophelis isolates were resistant to most $\beta$-lactams, $\beta$-lactam/ $\beta$-lactam inhibitor combinations, carbapenems, and aminoglycosides $[14,15,19,30,31,38]$ (Table 3). Nevertheless, over $90 \%$ of E. anophelis isolates in the Wisconsin outbreak were remarkably susceptible to cefepime [15]. A wide variation exists in the susceptibility of E. anophelis to piperacillin (19.5\%-100\%), piperacillin-tazobactam (30.6\%-92\%), ciprofloxacin $(1 \%-100 \%)$, levofloxacin $(16 \%-96 \%)$, trimethoprim-sulfamethoxazole $(4 \%-70.6 \%)$, and vancomycin $(0 \%-100 \%)$, whereas almost all E. anophelis isolates were notably susceptible to minocycline $(97.5 \%-100 \%)$. It is noteworthy that different testing methods could cause the variations in the susceptibility patterns observed among these studies, apart from the geographic variation.

Currently, over 60 deposited whole-genome sequences of E. anophelis are available in the GenBank. Whole-genome studies have revealed numerous putative genes associated with antibiotic resistance in E. anophelis $[15,44,47,71]$. These antimicrobial resistance-associated genes comprise genes conferring resistance to $\beta$-lactams (such as $b l a_{\mathrm{CME}-1}, b l a_{\mathrm{bla} B}$, and $b l a_{\mathrm{GOB}-4}$ ), aminoglycosides, fluoroquinolones, tetracycline, macrolides, chloramphenicol, vancomycin, trimethoprim, and multidrug resistance efflux pumps. Among these antibiotic resistance genes, mutations in the fluoroquinolone target genes have been well investigated. Investigations of E. anophelis isolates from the Wisconsin outbreak and from Taiwan have revealed that amino acid alterations at position 83 (Ser83Ile/Ser83Arg) and position 95 (Pro95Ser) in GyrA were associated with high-level fluoroquinolone resistance [15,18,19,70,72]. No nonsynonymous substitutions were recognized in GyrB, ParC, and ParE. Furthermore, gene mutations in the QRDRs occurred considerably less frequently in E. anophelis than they did in E. meningoseptica [19]. This finding is consistent with the fact that E. anophelis usually exhibited a substantially higher susceptibility rate to levofloxacin than E. meningoseptica did [19].

\subsection{Other Elizabethkingia Species}

Limited information presently exists regarding the antimicrobial susceptibility of the recently proposed E. bruuniana, E. ursingii, and E. occulta. A recent study described six E. bruuniana strains isolated from a clinical specimen in Taiwan [66]. Most isolates were resistant to $\beta$-lactams, $\beta$-lactam and lactamase inhibitors, carbapenems, aminoglycosides, and trimethoprim/sulfamethoxazole, but all these isolates were susceptible to minocycline. Two-thirds of isolates were susceptible to levofloxacin. 
However, no nonsynonymous substitutions in the QRDRs of $g y r A, \operatorname{gyr} B, \operatorname{par} C$, and $\operatorname{parE}$ were identified [66]

\section{Conclusions}

Elizabethkingia, particularly E. anophelis, has rapidly spread in several countries and causes lethally opportunistic infections in patients. Because numerous studies and clinical practice continue to rely on automated bacteriology identification systems for the identification of Elizabethkingia, upgrading MALDI-TOF MS with expanded reference databases or using molecular techniques to accurately identify these microorganisms is imperative. Considering that Elizabethkingia species are usually resistant to multiple antibiotics and that inappropriate antimicrobial therapy is an independent risk factor for mortality, early diagnosis and adequate antibiotic treatment are vital for patients with Elizabethkingia infection. Elizabethkingia demonstrates variable susceptibility to multiple antibiotics; therefore, treatment would be more reliable if guided by antimicrobial susceptibility testing. Minocycline has the potential to be the drug of choice for patients with Elizabethkingia infection. However, there is still a lack of clinical trials. Additional studies are required to determine optimal antimicrobial agents, either singly or in combination, for these life-threatening infections.

Author Contributions: Conceptualization, J.-N.L.; Data curation, J.-N.L., C.-H.L., C.-H.Y., and Y.-H.H.; Formal analysis, J.-N.L. and Y.-H.H.; Funding acquisition, J.-N.L.; Methodology, J.-N.L.; Resources, C.-H.L.; Supervision, J.-N.L.; Validation, J.-N.L., C.-H.L., C.-H.Y., and Y.-H.H.; Writing-original draft, J.-N.L. and C.-H.Y.; Writing-review and editing, J.-N.L., C.-H.L., C.-H.Y., and Y.-H.H.

Funding: This work was supported by grants EDPJ108068 from E-Da Hospital and MOST 106-2314-B-214-009-MY2 and 108-2314-B-214 -004 from the Ministry of Science and Technology, Taiwan.

Conflicts of Interest: The authors declare no conflict of interest.

\section{References}

1. Kim, K.K.; Kim, M.K.; Lim, J.H.; Park, H.Y.; Lee, S.-T. Transfer of Chryseobacterium meningosepticum and Chryseobacterium miricola to Elizabethkingia gen. nov. as Elizabethkingia meningoseptica comb. nov. and Elizabethkingia miricola comb. nov. Int. J. Syst. Evol. Microbiol. 2005, 55, 1287-1293. [CrossRef] [PubMed]

2. Nicholson, A.C.; Gulvik, C.A.; Whitney, A.M.; Humrighouse, B.W.; Graziano, J.; Emery, B.; Bell, M.; Loparev, V.; Juieng, P.; Gartin, J.; et al. Revisiting the taxonomy of the genus Elizabethkingia using whole-genome sequencing, optical mapping, and MALDI-TOF, along with proposal of three novel Elizabethkingia species: Elizabethkingia bruuniana sp. nov., Elizabethkingia ursingii sp. nov., and Elizabethkingia occulta sp. nov. Antonie Van Leeuwenhoek 2018, 111, 55-72. [PubMed]

3. Kämpfer, P.; Matthews, H.; Glaeser, S.P.; Martin, K.; Lodders, N.; Faye, I. Elizabethkingia anophelis sp. nov., isolated from the midgut of the mosquito Anopheles gambiae. Int. J. Syst. Evol. Microbiol. 2011, 61, 2670-2675. [CrossRef] [PubMed]

4. Jacobs, A.; Chenia, H.Y. Biofilm formation and adherence characteristics of an Elizabethkingia meningoseptica isolate from Oreochromis mossambicus. Ann. Clin. Microbiol. Antimicrob. 2011, 10, 16. [CrossRef] [PubMed]

5. Mee, P.T.; Lynch, S.E.; Walker, P.J.; Melville, L.; Duchemin, J.-B. Detection of Elizabethkingia spp. in Culicoides biting midges, Australia. Emerg. Infect. Dis. 2017, 23, 1409-1410. [CrossRef] [PubMed]

6. Hu, R.; Yuan, J.; Meng, Y.; Wang, Z.; Gu, Z. Pathogenic Elizabethkingia miricola infection in cultured black-spotted frogs, China, 2016. Emerg. Infect. Dis. 2017, 23, 2055-2059. [CrossRef]

7. Lei, X.P.; Yi, G.; Wang, K.Y.; OuYang, P.; Chen, D.F.; Huang, X.L.; Huang, C.; Lai, W.M.; Zhong, Z.J.; Huo, C.L.; et al. Elizabethkingia miricola infection in Chinese spiny frog (Quasipaa spinosa). Transbound. Emerg. Dis. 2019, 66, 1049-1053. [CrossRef] [PubMed]

8. Jiang, H.-Y.; Ma, J.-E.; Li, J.; Zhang, X.-J.; Li, L.-M.; He, N.; Liu, H.-Y.; Luo, S.-Y.; Wu, Z.-J.; Han, R.-C.; et al. Diets alter the gut microbiome of crocodile lizards. Front. Microbiol. 2017, 8, 2073. [CrossRef]

9. Moore, L.S.P.; Owens, D.S.; Jepson, A.; Turton, J.F.; Ashworth, S.; Donaldson, H.; Holmes, A.H. Waterborne Elizabethkingia meningoseptica in adult critical care. Emerg. Infect. Dis. 2016, 22, 9-17. [CrossRef] 
10. Yung, C.-F.; Maiwald, M.; Loo, L.H.; Soong, H.Y.; Tan, C.B.; Lim, P.K.; Li, L.; Tan, N.W.; Chong, C.-Y.; Tee, N.; et al. Elizabethkingia anophelis and association with tap water and handwashing, Singapore. Emerg. Infect. Dis. 2018, 24, 1730-1733. [CrossRef]

11. Teo, J.; Tan, S.Y.-Y.; Tay, M.; Ding, Y.; Kjelleberg, S.; Givskov, M.; Lin, R.T.P.; Yang, L. First case of E anophelis outbreak in an intensive-care unit. Lancet. 2013, 382, 855-856. [CrossRef]

12. King, E.O. Studies on a group of previously unclassified bacteria associated with meningitis in infants. Am. J. Clin. Pathol. 1959, 31, 241-247. [CrossRef] [PubMed]

13. Frank, T.; Gody, J.C.; Nguyen, L.B.L.; Berthet, N.; Le Fleche-Mateos, A.; Bata, P.; Rafaï, C.; Kazanji, M.; Breurec, S. First case of Elizabethkingia anophelis meningitis in the Central African Republic. Lancet 2013, 381, 1876. [CrossRef]

14. Lau, S.K.P.; Chow, W.-N.; Foo, C.-H.; Curreem, S.O.T.; Lo, G.C.-S.; Teng, J.L.L.; Chen, J.H.K.; Ng, R.H.Y.; $\mathrm{Wu}$, A.K.L.; Cheung, I.Y.Y.; et al. Elizabethkingia anophelis bacteremia is associated with clinically significant infections and high mortality. Sci. Rep. 2016, 6, 26045. [CrossRef] [PubMed]

15. Perrin, A.; Larsonneur, E.; Nicholson, A.C.; Edwards, D.J.; Gundlach, K.M.; Whitney, A.M.; Gulvik, C.A.; Bell, M.E.; Rendueles, O.; Cury, J.; et al. Evolutionary dynamics and genomic features of the Elizabethkingia anophelis 2015 to 2016 Wisconsin outbreak strain. Nat. Commun. 2017, 8, 15483. [CrossRef] [PubMed]

16. Navon, L.; Clegg, W.J.; Morgan, J.; Austin, C.; McQuiston, J.R.; Blaney, D.D.; Walters, M.S.; Moulton-Meissner, H.; Nicholson, A. Notes from the field: Investigation of Elizabethkingia anophelis cluster-Illinois, 2014-2016. MMWR 2016, 65, 1380-1381. [CrossRef] [PubMed]

17. Choi, M.H.; Kim, M.; Jeong, S.J.; Choi, J.Y.; Lee, I.-Y.; Yong, T.-S.; Yong, D.; Jeong, S.H.; Lee, K. Risk Factors for Elizabethkingia acquisition and clinical characteristics of patients, South Korea. Emerg. Infect. Dis. 2019, 25, 42-51. [CrossRef]

18. Lin, J.-N.; Lai, C.-H.; Yang, C.-H.; Huang, Y.-H.; Lin, H.-H. Clinical manifestations, molecular characteristics, antimicrobial susceptibility patterns and contributions of target gene mutation to fluoroquinolone resistance in Elizabethkingia anophelis. J. Antimicrob. Chemother. 2018, 73, 2497-2502. [CrossRef]

19. Lin, J.-N.; Lai, C.-H.; Yang, C.-H.; Huang, Y.-H. Comparison of clinical manifestations, antimicrobial susceptibility patterns, and mutations of fluoroquinolone target genes between Elizabethkingia meningoseptica and Elizabethkingia anophelis isolated in Taiwan. J. Clin. Med. 2018, 7, 538. [CrossRef]

20. Elizabethkingia. Available online: https://www.dhs.wisconsin.gov/disease/elizabethkingia.htm (accessed on 17 April 2017).

21. Recent Outbreaks, Elizabethkingia, CDC. Available online: https://www.cdc.gov/elizabethkingia/outbreaks/ (accessed on 26 December 2016).

22. Snesrud, E.; McGann, P.; Walsh, E.; Ong, A.; Maybank, R.; Kwak, Y.; Campbell, J.; Jones, A.; Vore, K.; Hinkle, M.; et al. Clinical and genomic features of the first cases of Elizabethkingia anophelis infection in New York, including the first case in a healthy infant without previous nosocomial exposure. J. Pediatr. Infect. Dis. Soc. 2018. [CrossRef]

23. Meier-Kolthoff, J.P.; Auch, A.F.; Klenk, H.-P.; Göker, M. Genome sequence-based species delimitation with confidence intervals and improved distance functions. BMC Bioinformatics 2013, 14, 60. [CrossRef] [PubMed]

24. Varghese, N.J.; Mukherjee, S.; Ivanova, N.; Konstantinidis, K.T.; Mavrommatis, K.; Kyrpides, N.C.; Pati, A. Microbial species delineation using whole genome sequences. Nucleic Acids Res. 2015, 43, 6761-6771. [CrossRef] [PubMed]

25. Vandamme, P.; Bernardet, J.-F.; Segers, P.; Kersters, K.; Holmes, B. New perspectives in the classification of the Flavobacteria: Description of Chryseobacterium gen. nov., Bergeyella gen. nov., and Empedobacter nom. rev. Int. J. Syst. Evol. Microbiol. 1994, 44, 827-831. [CrossRef]

26. Li, Y.; Kawamura, Y.; Fujiwara, N.; Naka, T.; Liu, H.; Huang, X.; Kobayashi, K.; Ezaki, T. Chryseobacterium miricola sp. nov., a novel species isolated from condensation water of space station Mir. Syst. Appl. Microbiol. 2003, 26, 523-528. [CrossRef] [PubMed]

27. Kämpfer, P.; Busse, H.-J.; McInroy, J.A.; Glaeser, S.P. Elizabethkingia endophytica sp. nov., isolated from Zea mays and emended description of Elizabethkingia anophelis Kämpfer et al. 2011. Int. J. Syst. Evol. Microbiol. 2015, 65, 2187-2193. [CrossRef] [PubMed] 
28. Doijad, S.; Ghosh, H.; Glaeser, S.; Kämpfer, P.; Chakraborty, T. Taxonomic reassessment of the genus Elizabethkingia using whole-genome sequencing: Elizabethkingia endophytica Kämpfer et al. 2015 is a later subjective synonym of Elizabethkingia anophelis Kämpfer et al. 2011. Int. J. Syst. Evol. Microbiol. 2016, 66, 4555-4559. [CrossRef] [PubMed]

29. Lin, J.-N.; Lai, C.-H.; Yang, C.-H.; Huang, Y.-H.; Lin, H.-F.; Lin, H.-H. Comparison of four automated microbiology systems with 16S rRNA gene sequencing for identification of Chryseobacterium and Elizabethkingia species. Sci. Rep. 2017, 7, 13824. [CrossRef] [PubMed]

30. Han, M.-S.; Kim, H.; Lee, Y.; Kim, M.; Ku, N.S.; Choi, J.Y.; Yong, D.; Jeong, S.H.; Lee, K.; Chong, Y. Relative prevalence and antimicrobial susceptibility of clinical isolates of Elizabethkingia species based on 16S rRNA gene sequencing. J. Clin. Microbiol. 2017, 55, 274-280. [CrossRef] [PubMed]

31. Cheng, Y.-H.; Perng, C.-L.; Jian, M.-J.; Cheng, Y.-H.; Lee, S.-Y.; Sun, J.-R.; Shang, H.-S. Multicentre study evaluating matrix-assisted laser desorption ionization-time of flight mass spectrometry for identification of clinically isolated Elizabethkingia species and analysis of antimicrobial susceptibility. Clin. Microbiol. Infect. 2019, 25, 340-345. [CrossRef] [PubMed]

32. Janda, J.M.; Abbott, S.L. 16S rRNA gene sequencing for bacterial identification in the diagnostic laboratory: Pluses, perils, and pitfalls. J. Clin. Microbiol. 2007, 45, 2761-2764. [CrossRef] [PubMed]

33. Adékambi, T.; Drancourt, M.; Raoult, D. The rpoB gene as a tool for clinical microbiologists. Trends Microbiol. 2009, 17, 37-45. [CrossRef] [PubMed]

34. Holmes, B.; Steigerwalt, A.G.; Nicholson, A.C. DNA-DNA hybridization study of strains of Chryseobacterium, Elizabethkingia and Empedobacter and of other usually indole-producing non-fermenters of CDC groups IIc, IIe, IIh and IIi, mostly from human clinical sources, and proposals of Chryseobacterium bernardetii sp. nov., Chryseobacterium carnis sp. nov., Chryseobacterium lactis sp. nov., Chryseobacterium nakagawai sp. nov. and Chryseobacterium taklimakanense comb. nov. Int. J. Syst. Evol. Microbiol. 2013, 63, 4639-4662. [PubMed]

35. Pei, A.Y.; Oberdorf, W.E.; Nossa, C.W.; Agarwal, A.; Chokshi, P.; Gerz, E.A.; Jin, Z.; Lee, P.; Yang, L.; Poles, M.; et al. Diversity of $16 \mathrm{~S}$ rRNA genes within individual prokaryotic genomes. Appl. Environ. Microbiol. 2010, 76, 3886-3897. [CrossRef] [PubMed]

36. Walsh, D.A.; Bapteste, E.; Kamekura, M.; Doolittle, W.F. Evolution of the RNA polymerase B' subunit gene $\left(r p o B^{\prime}\right)$ in Halobacteriales: A complementary molecular marker to the SSU rRNA gene. Mol. Biol. Evol. 2004, 21, 2340-2351. [CrossRef] [PubMed]

37. Rowland, G.C.; Aboshkiwa, M.; Coleman, G. Comparative sequence analysis and predicted phylogeny of the DNA-dependent RNA polymerase beta subunits of Staphylococcus aureus and other eubacteria. Biochem. Soc. Trans. 1993, 21, 40S. [CrossRef]

38. Chew, K.L.; Cheng, B.; Lin, R.T.P.; Teo, J.W.P. Elizabethkingia anophelis is the dominant Elizabethkingia species found in blood cultures in Singapore. J. Clin. Microbiol. 2018, 56, e01445. [CrossRef] [PubMed]

39. Kelly, A.J.; Karpathy, S.E.; Gulvik, C.A.; Ivey, M.L.; Whitney, A.M.; Bell, M.E.; Nicholson, A.C.; Humrighouse, B.H.; McQuiston, J.R. A real-time multiplex PCR assay for detection of Elizabethkingia species, and differentiating between E. anophelis and E. meningoseptica. J. Clin. Microbiol. 2019, 57, e01619. [CrossRef]

40. Goris, J.; Konstantinidis, K.T.; Klappenbach, J.A.; Coenye, T.; Vandamme, P.; Tiedje, J.M. DNA-DNA hybridization values and their relationship to whole-genome sequence similarities. Int. J. Syst. Evol. Microbiol. 2007, 57, 81-91. [CrossRef]

41. Richter, M.; Rosselló-Móra, R. Shifting the genomic gold standard for the prokaryotic species definition. Proc. Natl. Acad. Sci. USA 2009, 106, 19126-19131. [CrossRef]

42. Konstantinidis, K.T.; Tiedje, J.M. Genomic insights that advance the species definition for prokaryotes. Proc. Natl. Acad. Sci. USA 2005, 102, 2567-2572. [CrossRef]

43. Lin, J.-N.; Lai, C.-H.; Yang, C.-H.; Huang, Y.-H.; Lin, H.-H. Genomic features, comparative genomics, and antimicrobial susceptibility patterns of Elizabethkingia bruuniana. Sci. Rep. 2019, 9, 2267. [CrossRef] [PubMed]

44. Lin, J.-N.; Lai, C.-H.; Yang, C.-H.; Huang, Y.-H.; Lin, H.-H. Genomic features, phylogenetic relationships, and comparative genomics of Elizabethkingia anophelis strain EM361-97 isolated in Taiwan. Sci. Rep. 2017, 7, 14317. [CrossRef] [PubMed]

45. Eriksen, H.B.; Gumpert, H.; Faurholt, C.H.; Westh, H. Determination of Elizabethkingia diversity by MALDI-TOF mass spectrometry and whole-genome sequencing. Emerg. Infect. Dis. 2017, 23, 320-323. [CrossRef] [PubMed] 
46. Lin, J.-N.; Lai, C.-H.; Yang, C.-H.; Huang, Y.-H.; Lin, H.-H. Complete genome sequence of Elizabethkingia miricola strain EM798-26 isolated from the blood of a cancer patient. Genome Announc. 2018, 6, e01408. [CrossRef] [PubMed]

47. Breurec, S.; Criscuolo, A.; Diancourt, L.; Rendueles, O.; Vandenbogaert, M.; Passet, V.; Caro, V.; Rocha, E.P.C.; Touchon, M.; Brisse, S. Genomic epidemiology and global diversity of the emerging bacterial pathogen Elizabethkingia anophelis. Sci. Rep. 2016, 6, 30379. [CrossRef] [PubMed]

48. Da Silva, P.S.L.; Pereira, G.H. Elizabethkingia meningoseptica: Emergent bacteria causing pneumonia in a critically ill child. Pediatr. Int. 2013, 55, 231-234. [CrossRef] [PubMed]

49. Lin, P.-Y.; Chu, C.; Su, L.-H.; Huang, C.-T.; Chang, W.-Y.; Chiu, C.-H. Clinical and microbiological analysis of bloodstream infections caused by Chryseobacterium meningosepticum in nonneonatal patients. J. Clin. Microbiol. 2004, 42, 3353-3355. [CrossRef]

50. Lin, Y.-T.; Chiu, C.-H.; Chan, Y.-J.; Lin, M.-L.; Yu, K.-W.; Wang, F.-D.; Liu, C.-Y. Clinical and microbiological analysis of Elizabethkingia meningoseptica bacteremia in adult patients in Taiwan. Scand. J. Infect. Dis. 2009, 41, 628-634. [CrossRef]

51. Hung, P.-P.; Lin, Y.-H.; Lin, C.-F.; Liu, M.-F.; Shi, Z.-Y. Chryseobacterium meningosepticum infection: Antibiotic susceptibility and risk factors for mortality. J. Microbiol. Immunol. Infect. 2008, 41, 137-144.

52. Hsu, M.-S.; Liao, C.-H.; Huang, Y.-T.; Liu, C.-Y.; Yang, C.-J.; Kao, K.-L.; Hsueh, P.-R. Clinical features, antimicrobial susceptibilities, and outcomes of Elizabethkingia meningoseptica (Chryseobacterium meningosepticum) bacteremia at a medical center in Taiwan, 1999-2006. Eur. J. Clin. Microbiol. Infect. Dis. 2011, 30, 1271-1278. [CrossRef]

53. Huang, Y.-C.; Huang, Y.-W.; Lin, Y.-T.; Wang, F.-D.; Chan, Y.-J.; Yang, T.-C. Risk factors and outcome of levofloxacin-resistant Elizabethkingia meningoseptica bacteraemia in adult patients in Taiwan. Eur. J. Clin. Microbiol. Infect. Dis. 2017, 36, 1373-1380. [CrossRef] [PubMed]

54. Huang, Y.-C.; Lin, Y.-T.; Wang, F.-D. Comparison of the therapeutic efficacy of fluoroquinolone and non-fluoroquinolone treatment in patients with Elizabethkingia meningoseptica bacteraemia. Int. J. Antimicrob. Agents 2018, 51, 47-51. [CrossRef] [PubMed]

55. Chen, W.-C.; Chen, Y.-W.; Ko, H.-K.; Yu, W.-K.; Yang, K.-Y. Comparisons of clinical features and outcomes between Elizabethkingia meningoseptica and other glucose non-fermenting Gram-negative bacilli bacteremia in adult ICU patients. J. Microbiol. Immunol. Infect. 2018. [CrossRef] [PubMed]

56. Huang, Y.-C.; Wu, P.-F.; Lin, Y.-T.; Wang, F.-D. Comparison of clinical characteristics of bacteremia from Elizabethkingia meningoseptica and other carbapenem-resistant, non-fermenting Gram-negative bacilli at a tertiary medical center. J. Microbiol. Immunol. Infect. 2019, 52, 304-311. [CrossRef] [PubMed]

57. Rastogi, N.; Mathur, P.; Bindra, A.; Goyal, K.; Sokhal, N.; Kumar, S.; Sagar, S.; Aggarwal, R.; Soni, K.D.; Tandon, V. Infections due to Elizabethkingia meningoseptica in critically injured trauma patients: A seven-year study. J. Hosp. Infect. 2016, 92, 30-32. [CrossRef] [PubMed]

58. Lin, P.-Y.; Chen, H.-L.; Huang, C.-T.; Su, L.-H.; Chiu, C.-H. Biofilm production, use of intravascular indwelling catheters and inappropriate antimicrobial therapy as predictors of fatality in Chryseobacterium meningosepticum bacteraemia. Int. J. Antimicrob. Agents 2010, 36, 436-440. [CrossRef]

59. Bloch, K.C.; Nadarajah, R.; Jacobs, R. Chryseobacterium meningosepticum: An emerging pathogen among immunocompromised adults. Report of 6 cases and literature review. Medicine (Baltimore) 1997, 76, 30-41. [CrossRef]

60. Green, O.; Murray, P.; Gea-Banacloche, J.C. Sepsis caused by Elizabethkingia miricola successfully treated with tigecycline and levofloxacin. Diagn. Microbiol. Infect. Dis. 2008, 62, 430-432. [CrossRef]

61. Colapietro, M.; Endimiani, A.; Sabatini, A.; Marcoccia, F.; Celenza, G.; Segatore, B.; Amicosante, G.; Perilli, M. BlaB-15, a new BlaB metallo- $\beta$-lactamase variant found in an Elizabethkingia miricola clinical isolate. Diagn. Microbiol. Infect. Dis. 2016, 85, 195-197. [CrossRef]

62. Opota, O.; Diene, S.M.; Bertelli, C.; Prod'hom, G.; Eckert, P.; Greub, G. Genome of the carbapenemase-producing clinical isolate Elizabethkingia miricola EM_CHUV and comparative genomics with Elizabethkingia meningoseptica and Elizabethkingia anophelis: Evidence for intrinsic multidrug resistance trait of emerging pathogens. Int. J. Antimicrob. Agents 2017, 49, 93-97. [CrossRef]

63. Zdziarski, P.; Paściak, M.; Rogala, K.; Korzeniowska-Kowal, A.; Gamian, A. Elizabethkingia miricola as an opportunistic oral pathogen associated with superinfectious complications in humoral immunodeficiency: A case report. BMC Infect. Dis. 2017, 17, 763. [CrossRef] [PubMed] 
64. Kenna, D.T.D.; Fuller, A.; Martin, K.; Perry, C.; Pike, R.; Burns, P.J.; Narayan, O.; Wilkinson, S.; Hill, R.; Woodford, N.; et al. rроB gene sequencing highlights the prevalence of an E. miricola cluster over other Elizabethkingia species among UK cystic fibrosis patients. Diagn. Microbiol. Infect. Dis. 2018, 90, 109-114. [CrossRef] [PubMed]

65. Lau, S.K.P.; Wu, A.K.L.; Teng, J.L.L.; Tse, H.; Curreem, S.O.T.; Tsui, S.K.W.; Huang, Y.; Chen, J.H.K.; Lee, R.A.; Yuen, K.-Y.; et al. Evidence for Elizabethkingia anophelis transmission from mother to infant, Hong Kong. Emerg. Infect. Dis. 2015, 21, 232-241. [CrossRef] [PubMed]

66. Fraser, S.L.; Jorgensen, J.H. Reappraisal of the antimicrobial susceptibilities of Chryseobacterium and Flavobacterium species and methods for reliable susceptibility testing. Antimicrob. Agents Chemother. 1997, 41, 2738-2741. [CrossRef] [PubMed]

67. Lin, J.-N.; Lai, C.-H.; Yang, C.-H.; Huang, Y.-H. Elizabethkingia bruuniana infections in humans, Taiwan, 2005-2017. Emerg Infect Dis. 2019, 25, 1412-1414. [CrossRef] [PubMed]

68. Tai, I.-C.; Liu, T.-P.; Chen, Y.-J.; Lien, R.-I.; Lee, C.-Y.; Huang, Y.-C. Outbreak of Elizabethkingia meningoseptica sepsis with meningitis in a well-baby nursery. J. Hosp. Infect. 2017, 96, 168-171. [CrossRef] [PubMed]

69. Chen, S.; Soehnlen, M.; Walker, E.D. Genome sequence of Elizabethkingia meningoseptica EM1, isolated from a patient with a bloodstream infection. Genome Announc. 2016, 4, e01137. [CrossRef]

70. Jian, M.-J.; Cheng, Y.-H.; Perng, C.-L.; Shang, H.-S. Molecular typing and profiling of topoisomerase mutations causing resistance to ciprofloxacin and levofloxacin in Elizabethkingia species. Peer J. 2018, 6, e5608. [CrossRef]

71. Li, Y.; Liu, Y.; Chew, S.C.; Tay, M.; Salido, M.M.S.; Teo, J.; Lauro, F.M.; Givskov, M.; Yang, L. Complete genome sequence and transcriptomic analysis of the novel pathogen Elizabethkingia anophelis in response to oxidative stress. Genome Biol. Evol. 2015, 7, 1676-1685. [CrossRef]

72. Jian, M.-J.; Cheng, Y.-H.; Chung, H.-Y.; Cheng, Y.-H.; Yang, H.-Y.; Hsu, C.-S.; Perng, C.-L.; Shang, H.-S. Fluoroquinolone resistance in carbapenem-resistant Elizabethkingia anophelis: Phenotypic and genotypic characteristics of clinical isolates with topoisomerase mutations and comparative genomic analysis. J. Antimicrob. Chemother. 2019, 74, 1503-1510.

(C) 2019 by the authors. Licensee MDPI, Basel, Switzerland. This article is an open access article distributed under the terms and conditions of the Creative Commons Attribution (CC BY) license (http://creativecommons.org/licenses/by/4.0/). 